\title{
“COMUNISMO SIN COMUNIDAD”: NOTAS SOBRE ONTOLOGÍA, ÉTICA Y POLÍTICA EN EL PENSAMIENTO DE JEAN-LUC NANCY
}

\author{
"Communism without community": notes on ontology, ethics and politics in the thinking of Jean- \\ Luc Nancy \\ Iván Torres Apablaza \\ Universidad Andrés Bello, Santiago, Chile \\ ivantorresapablaza@gmail.com
}

\section{Resumen}

El artículo reconstruye las coordenadas del problema de lo común en el pensamiento de Jean-Luc Nancy, intentando con ello ofrecer al lector un diagrama sobre un aspecto cardinal de su trabajo filosófico, aun cuando no siempre se lo aborde desde este ángulo. En este escenario, se desarrolla la problematicidad ontológica que recorre el pensamiento de lo común para arribar a un examen de la juntura o prolongación entre lo ético y lo político. El artículo concluye, luego de haber pensado el carácter disyunto de lo común, con una propuesta interpretativa sobre una politicidad de la existencia que intenta comparecer a la reelaboración de un concepto desfundamentado y abisal de lo político, esto es, a un ethos de la comparecencia al carácter relacional y diferencial de la existencia.

Palabras clave: común, comunidad, ontología, ética, política.

\begin{abstract}
The article establishes the coordinates of the problem of the common in the thought of Jean-Luc Nancy, trying in this way to offer the reader a diagram about a cardinal aspect of his philosophical work, even though it is not always approached from this angle. On this stage, the ontological problematic that passes through the thought of the common develops to arrive at an examination of the junction between the ethical and the political. The article concludes, after having thought about the disjunct character of the common, with an interpretative proposal about a politicity of existence that tries to compear at the reelaboration of an unfounded and abysmal concept of the political, that is, to an ethos of co-appearance to the relational and differential character of existence.
\end{abstract}

Keywords: common, community, ontology, ethics, politics.

Fecha de Recepción: 29/07/2019 - Fecha de Aceptación: 26/11/2019 


\section{Situación del problema}

El contexto de la discusión sobre lo que, en primera instancia, Jean-Luc Nancy denomina el problema de la «comunidad», tiene su gesto inaugural con la publicación el año 1983 del ensayo La communauté désoeuvrée. Allí, su propósito consistía en re-posicionar un debate que, a la luz del desastre de las experiencias filosóficas y políticas fundadas en nombre de lo común ${ }^{1}$, fue abandonado, tanto en un terreno como en otro, poniendo en cuestión precisamente al nosotros mismo, aspecto que reaparecerá con distintas intensidades y a propósito de distintas figuras a lo largo de su pensamiento. Siguiendo este itinerario, propondrá pensar «lo común» recusando cualquier posibilidad de hacer de este algo sustantibable u objetivable. Las experiencias de exterminio y barbarie que suponen las políticas fundadas sobre un dato de lo común (raza, clase, nación), impiden precisamente esta posibilidad.

La "pulsión" escritural, intentaba volver con este gesto a la "exigencia comunista" (2000 49), con objeto de aproximar -como aclarará más tarde-, el motivo de la comunidad a la categoría de comunismo (cf. 2016 13-14), sobre todo considerando la experiencia disolutiva de lo común que acontece junto al desastre moderno del totalitarismo; tensión que se encarna en la aporía que ronda históricamente su anfibología: unas veces como "comunidad del pueblo" (Volkgemeinschaft) y otras en la forma de "comunismo" (cf. 2007 17-21). Por ello, Nancy dirá que "la comunidad está por pensarse..." (2000 49), toda vez que el pensamiento al que refiere es aquel de una filosofía primera u ontología del ser-encomún, que es precisamente la textura que en adelante asumirá su problematización. Lo propiamente désoeuvré -desobrado, inoperante, inútil o improductivo - de la comunidad, intentaba nombrar así aquello que le concierne como lo más propio, esto es, como aquello completamente retirado de la productividad y la obra, completamente interrumpido o en condición suspensiva respecto a su objetividad en tanto ser cosa. La «comunidad» así pensada, no será, entonces, sino lo más banal ( $c f .2016$ 14) y aquello ante lo cual comparecemos ( $c f$. 2014 68), en cuanto disposición de las singularidades que son condición de existencia, su estar suspendida en su propio límite, "el elemento de una igualdad primordial e irreductible a todo efecto de distinción" (2016 14) que vuelve inoperante la "obra comunitaria" en su forma social, económica, técnica e institucional. Así dispuesto, el desobramiento o inoperancia de la comunidad, no será sino una negatividad que posibilita que la compartición del ser sólo pueda ser

\footnotetext{
${ }^{1}$ Fundamentalmente el marxismo aplicado a las experiencias socialistas de Europa del este, pero también el fantasma del fascismo y el nazismo que recorre las experiencias políticas europeas del siglo XX.
} 
dicha deshaciendo el ser (sustantivo, sujeto) en su acto (verbo, transitividad) (cf. 2016 20-23).

Reconstruir este debate no es una tarea sencilla, por tratarse de un aspecto del pensamiento filosófico-político contemporáneo que no ha dejado de concitar tanto para él mismo, como en su irradiación a otros campos - un conjunto de disputas teóricas, políticas y filosóficas. Al mismo tiempo, existe una muy diversa bibliografía sobre la cuestión, que dificulta cualquier intento de ordenamiento o sistematización de un problema que, precisamente, no puede sino permanecer abierto. Finalmente, se trata de un punto cardinal que recorre el pensamiento de Jean-Luc Nancy, aun cuando no siempre se lo reconozca, ni se lo lea desde el ángulo de los problemas filosófico-políticos que ha dispuesto, privilegiando, en cambio, el problema estético. Advertidos de esta complejidad, intentaré, de todos modos, proponer algunas estancias desde las cuales abordar el problema de lo común, para rastrear allí los indicios de la re-conceptualización de lo político a partir de la cual Nancy inaugura su interrogación. Una de las consecuencias que interesa resaltar con esta operación analítica, es la indisociable relación entre ética y política contenida en dicha re-conceptualización.

\section{La ontología relacional de lo común}

La primera estancia que habría que tener en cuenta, sobre problema de lo común en Nancy, consiste en atender a las tensiones a las que se enfrenta el pensamiento de la comunidad, las que, al mismo tiempo, constituyen la condición de su despliegue. En este registro, es posible identificar una exhortación a interrogar la tradición de pensamiento sobre la «comunidad $»^{2}$, que tiende a representarla como lugar encontrado o realizado, cuestión problemática no tan sólo por el carácter de obra acabada (absoluta) que supone, sino porque lo que pone en el centro es al hombre y su pretendida definición: productor de obras en tanto suyas, en tanto esencias de su propia producción. La comunidad, así entendida, no podría ser entonces otra cosa que una comunidad humana, tributaria de "una inmanencia absoluta del hombre al hombre -un humanismo- y de la comunidad a la comunidad -un comunismo..." (2000 21). Sin embargo, de esta lectura se sigue que una comunidad que pone en el centro al hombre como el propietario de lo común, tendría por contrapartida su afirmación en tanto esencia realizada del hombre mismo, en un escenario histórico completamente problemático, en que las obras del humanismo lo han sido todo "menos un legado de humanidad...[configurando] un mundo que no logra hacer mundo, un mundo

\footnotetext{
${ }^{2}$ En filosofía, pero también en la teoría política y en las ciencias sociales en general.
} 
enfermo de mundo y de sentido del mundo" (2016 12), es decir, una comunidad internamente desgarrada.

Esto es precisamente lo que para Nancy constituye el escollo de un pensamiento de la comunidad y por ello, las posibilidades de pensar lo común no podrían sino transitar por una crítica sin reservas al humanismo y sus consecuencias filosóficas, políticas y culturales en Occidente. Más aún, cuando lo que está en juego es precisamente una oposición crítica al individualismo que esta concepción supone, puesto que la «comunidad de los hombres» no sería otra cosa que la comunidad de individuos ${ }^{3}$, en tanto expresa "(...) el residuo que deja la disolución de la comunidad" (2000 22), y como tal, en cuanto figuración de lo indiviso, "revela ser el resultado abstracto de una descomposición...[la] figura simétrica de la inmanencia: el para-sí absolutamente desprendido, tomado como origen y como certeza" (Ibid.). De todos modos, y en abierta oposición crítica al inmanentismo 4 que nos recorre, Nancy dirá que "no se hace un mundo con simples átomos. Hace falta un clinamen...una inclinación del uno hacia el otro, del uno por el otro o del uno al otro. La comunidad es al menos el clinamen del «individuo»" (2000 22, 23), su inclinación fuera de sí mismo (ex-tático) sobre el borde que es su estar-en-común. Por ello, el pensamiento de la comunidad no podría constituir un nuevo humanismo, puesto que "no tiene nada de antropocéntrico: no sitúa al hombre en el centro de la «creación», cruza al contrario por el hombre...como su desmesura imposible de totalizar: su infinita singularidad original" (2006 33), donde los hombres no hacemos más que exponer la existencia del conjunto de los entes que somos: estar-en-común como "ser juntos" o «ser-en-el-mundo», es entonces, antes que un ser entre los hombres, los otros considerados como todos los entes en general, en la medida que lo común como condición esencial del ser, es condición de proximidad, de intercambio, de exposición recíproca entre la totalidad de los entes (cf. 1998 15-16). En Etre singulier pluriel - con una distancia de trece años de La communauté désoeuvrée - Nancy precisa este aspecto y aclara que de lo que se trata es de pensar en una ontología de los cuerpos "inanimados, animados, sensibles, parlantes, pensantes, pesantes. "Cuerpo» quiere ante todo y en efecto decir: lo que está fuera, como afuera, al lado, contra, cerca, con (otro) cuerpo, en el cuerpo a cuerpo, en la dis-posición..." (2006 100) y en la exposición que pone al hombre fuera de lo humano, abriéndolo al mundo donde los entes se tocan.

\footnotetext{
${ }^{3}$ Cuestión que también podría ser formulada como una crítica al concepto de sujeto construido por la modernidad, esto es, fundamentalmente subjetctum en tanto soporte o base subyacente de sí mismo y lo real.

${ }^{4}$ Que no es sino una categoría filosófica para nombrar el totalitarismo.
} 
El problema de lo común así planteado, se vuelve una clave de interrogación por nuestro presente, al advertir el modo en que este se ha constituido como pura inmanencia, de modo tal que lo que conocemos como totalitarismo no sería otra cosa que el extremo de la "pulsión" inmanentista que recorre la "pasión moderna" de presuposición y constitución de la existencia como obra autoproducida; obra cerrada sobre sí misma, sin afuera, ab-soluta. En un escenario de estas características, el individuo y el Estado total, serían formas o expresiones de la metafísica del sujeto, del para-sí absoluto del ser, perfectamente desprendido y clausurado, sin relación. Por contrapartida, la pregunta por la comunidad vendría a deshacer la "autarquía de la inmanencia absoluta" (2000 24) - ya sea que se exprese como individualidad, Estado o colectividad total-, en la medida que expone la desgarradura "entre la totalidad de las cosas que son considerada como lo absoluto...- y el ser...por lo cual o en nombre de lo cual estas cosas, en totalidad, son ${ }^{5 \prime \prime}$ (2000 25). Precisamente, porque esta diferencia define y le impone una relación al absoluto con su propio ser y es lo que Nancy quiere proponer como un pensamiento del ser en tanto pensamiento de la comunidad, en la medida que "es el ser mismo el que llega a definirse como relación" (Ibid.).

\section{Dis-yunción de lo común}

Un antecedente fundamental y sin el cual no es posible entender esta concepción ontológico-relacional de lo común, se encuentra en los trabajos previos a $\mathrm{La}$ communauté désoeuvrée, desarrollados en colaboración con Philippe LacoueLabarthe, particularmente aquellos publicados entre 1979 y 1983 en el marco de las actividades del Centre de Recherches Philosophiques sur le Politique ${ }^{6}$, puesto que nos permite advertir, por un lado, el lugar desde el cuál habla Nancy cuando piensa el problema de lo común, poniendo especial acento en la interrogación por lo político ${ }^{7}$ y por otro, el trayecto seguido entre las tesis filosófico-políticas sostenidas allí y la reflexión ontológica posterior sobre el ser-en-común. Teniendo esto en cuenta, es posible observar que la textura o el tono escritural de Jean-Luc Nancy, se encuentra recorrido por un desencanto con la política, con todas las implicancias semánticas que esta denominación podría llegar a tener para un pensamiento de la existencia, y una radicalidad tal que en su gesto clausura la posibilidad misma de

\footnotetext{
${ }^{5}$ Diferencia, aclara Nancy, análoga o idéntica a la diferencia ontológica en Heidegger.

${ }^{6}$ El ensayo de 1979 titulado La panique politique constituye un antecedente directo del trabajo que desarrollarán a partir del año 1981 en dicho Centro.

7 Hay aquí una distinción conceptual entre la política, determinada, instrumental, fundamentalmente técnica y lo político ligado más bien a una politicidad, a una relación más originaria que la política de carácter óntica.
} 
calcular, prever o proyectar cualquier pretensión salvífica de ella. Esta tonalidad, sin embargo, se encuentra lejos de constituir una nueva versión del nihilismo vulgar. Antes bien, es la afirmación del nihil en tanto negación de cualquier necesidad en la forma retroactiva de una origen o preexistencia, o en la forma prospectiva de una comunión, puesto que la existencia - en esta concepción- es con o nada existe, cuestión que impide afirmar cualquier forma de pre-suposición del ser, a menos que sea esta misma nada ( $c f .2006$ 21-26). Lo que se afirma, en cambio, y a lo que se permanece fiel es al carácter dis-oluto del origen, en el sentido de una relación dis-yunta como escena originaria del ser-en-común. Por medio de este gesto, Nancy consigue formular una noción desfundamentada de la comunidad. En Être singulier pluriel, esta misma concepción reaparecerá con toda claridad para expresar que, "de una singularidad a otra hay contigüidad, pero sin continuidad. Hay proximidad, pero en la medida que lo extremo de lo próximo acusa la distancia que lo aumenta. Todo ser toca a cualquier otro, pero la ley del tacto es la separación...es la heterogeneidad de las superficies que se tocan" (2006 21).

En La panique politique (2013), problematizará precisamente este aspecto, interrogando el carácter originario de la relación (social), al plantearla como el problema de la co-existencia, en tanto aquello que concierne a lo político y a partir de lo cual este "comienza a constituir un problema" (Id. 15), al posibilitar que la política, así como cualquier forma de asociación, puedan efectivamente llegar a tener lugar. Particularmente, en este ensayo, esta reflexión será planteada como la necesidad de abandonar toda pretensión política fundada en un sujeto, así como en cualquier subjetividad de lo político, afirmando, en cambio, una no-subjetividad como figura que permita pensar aquella escena más originaria que toda subjetividad y toda política, "responsable" de grabar el límite del sujeto al mismo tiempo que el de lo político. El poder, desde esta perspectiva, no constituiría "la última cuestión ni la primera instancia" (Id. 29), sino el fondo de una no-relación, a contrapelo de las formulaciones tradicionales en el pensamiento occidental ${ }^{8}$ que dan por sentada la relación (social), ofreciéndonos al sujeto como su más directa encarnación. En sus propias palabras, el politikòn zōon griego "nunca ensambla otra cosa que aquello que, por sí, se desensambla y se excluye" (Ibid.). Por ello dirán que "en el principio está la anarquía, lo cual quiere decir, precisamente que no hay arquía, ni «anárquica» ni «monárquica»" (2013 42), puesto que lo que se intenta

\footnotetext{
${ }^{8}$ Salvo contadas excepciones, como Freud en los llamados "escritos culturalistas", Hobbes con la figura de "la guerra de todos contra todos", o incluso en cierta sociología funcionalista. No obstante, en todos estos casos, esta comprensión no hace otra cosa que constituir un argumento a favor de un pensamiento del orden, en la forma de la renuncia pulsional, el Leviatán o un proceso de socialización e integración social.
} 
afirmar es la alter-ación de origen en la relación. En Être singulier pluriel, Nancy recuperará esta textura del problema para precisar que "acceder" al origen equivale a exponerse a una verdad: la pluralidad indefinida de los orígenes y la coexistencia originaria. Lo cual significa que nunca accedemos al origen, puesto que este se sustrae en su multiplicidad alterada como ser-otro. En consecuencia, cuando se piensa lo común, no podríamos perder de vista el carácter singular plural de la existencia (2006). Es esta la constitución de esencia -o, co-esencia- del ser que lo disloca como unidad e identidad. De todos modos, aclara Nancy, "esto no es, sin embargo, más que una manera de hablar, ya que no hay ninguna sustancia previa que viniera a ser disuelta. El ser no preexiste a su singular-plural" (Ibid. 44), no preexiste a nada, más bien existe puesto que co-existe.

El problema filosófico-político de la comunidad, es desplazado así, al terreno ontológico de un pensamiento sobre el ser considerado como lo ex-tático, lo abierto, y lo expuesto, lo "fuera de sí" como su dimensión constitutiva. La dirección a la que conduce, es hacia la cuestión de la singularidad, en tanto constituye el reverso exacto de lo absoluto, puesto que esta no tiene lugar como individualidad, sino más bien "en el plano del clinamen, inidentificable" (2000 26). $\mathrm{Y}$ este tener lugar no es otro que el de la relación, puesto que el modo de existencia de la singularidad no es sino el estar en relación, su ser- $\operatorname{con}^{9}$, desplegando así lo que más tarde Nancy formulará como una concepción singular de la diferencia, o de la diferencia singular, es decir, ontológicamente "inscrita" (cf. 2006 21-26).

De todos modos, no habría que perder de vista lo que acabo de señalar, esto es, que la relación a la que apela el ser-con, en ningún caso es la de una existencia fusional, domesticada o pacífica, sino la de una no-relación, o más bien, de una relación dis-yunta ${ }^{10}$. Por ello la relación (el ser como relación), al igual que la comunidad, están por pensarse, en dirección a una comprensión del estar extático del ser como su condición más originaria que disponga el pensamiento tal como Nancy lo encuentra en Blanchot (1968) - hacia un comunismo sin herencia, es decir, como aquello que excluye y se excluye de toda comunidad pre-supuesta a partir de una cierta sustancia o principio trascendente que pudiese darle un contenido que le fuese propio. Por el contrario, una comunidad identificada con la inmanencia no encontraría más verdad que en la muerte, al extraviar su singularidad y permanecer como la identidad de los átomos, en una condición absoluta que precisamente la niega, en tanto su ser es relación, su estar referida a lo

\footnotetext{
${ }^{9}$ Lo singular, por ello, es siempre plural. Siempre se trata de singularidades.

${ }^{10}$ Las palabras utilizadas por Lacoue-Labarthe y Nancy en el Avertissement a Le retrait du politique, son déliaison (desligazón) y dissociation (disociación).
} 
singular ligado-desligado ${ }^{11}$. Los desastres políticos en la Europa de mediados del siglo XX se vuelven comunidades de muerte, precisamente por una voluntad de inmanencia absoluta de este tipo: "la inmanencia, la fusión comulgante, no encierra otra lógica que la del suicidio de esa comunidad que se regula con ella" (2000 34). Muerte de la comunidad como realización infinita de una vida inmanente. Para Nancy este aspecto del problema resulta ser crucial ya que, contrariamente a la operación inmanentista sobre la comunidad, la muerte es precisamente lo que revela el carácter finito del estar-juntos, el co-estar que es la comunidad, como lo suyo más propio, "consistiendo" como abierta o desobrada, es decir, "alrededor de la "pérdida" (de la imposibilidad) de su inmanencia" (Id. 37). El problema así planteado, excederá y recusará irremediablemente cualquier recurso o amparo en una metafísica del sujeto, al mismo tiempo que nos expondrá al carácter menesteroso y no dialectizable de la existencia.

\section{Mitdasein y arrealización de lo común}

En este gesto podría exponerse mínimamente la propuesta ontológica de Jean-Luc Nancy, la que constituye una crítica al mismo tiempo que una radicalización de la ontología heideggeriana del Mitsein, Mit-dasein contenida en Sein und Zeit (1927) ${ }^{12}$, con la que -en sus palabras - no cabría sino un vínculo de "Destruktion o deconstrucción" (2006 37) - para entender que el mit (con) no califica al sein, como si el ser subsistiera por sí mismo, sino que más bien constituye esencialmente al dasein: "en un alemán barroco -añade Nancy- diría que se trata del «seindamit», o del «con» como modalidad propia, exclusiva y originaria del estar-ahí o del ser-elahí" (2000 140), puesto que el ahí no constituye un suelo para la existencia sino su tener-lugar, su arribo, y también "su diferencia, su retirada, su exceso, su excripción" (Id. 141). En el prólogo a Communitas, de Roberto Esposito, Nancy precisará que el prefijo con se ha puesto de relieve en tanto rasgo esencial de la existencia, modo de pensar entonces la existencia en común, es decir "la existencia a secas" (1998 10) o "la condición coexistente que nos es co-esencial" (Id. 13). Por esta razón, la posición del ser será pensada como una ex-posición, intentando connotar, precisamente, que el ser se encuentra originaria y esencialmente expuesto. Es esto lo que Nancy piensa como el sentido del ser en tanto aquello que somos nosotros mismos: el sentido del ser como su propia co-municación, antes que

\footnotetext{
${ }^{11}$ Es decir, a una singularidad que no hace obra, sino que existe en la forma de la relación con otras singularidades, en tanto diferencia que no deja de diferenciarse.

12 En este punto del problema, el análisis de Nancy se concentra en el capítulo IV de Sein und Zeit, específicamente, en el parágrafo 26. Para esta investigación, se ha tenido en cuenta la traducción de José Gaos (2007), publicada por Fondo de Cultura Económica.
} 
un predicado o propiedad que se añadiría al ser (2006 17-20); explosión de la presencia en la multiplicidad originaria de su partición.

Esta relectura crítica de Heidegger, le permitirá pensar a Nancy la existencia, el Dasein, como co-estar, lo común sin comunidad, sin existencia fusional u obrada, pero teniendo en cuenta que este co-estar o ser-con (mitsein), de singularidades diferentes que no dejan de diferenciarse, es el de la finitud de la existencia, el de un ser-con vuelto-hacia-la-muerte. Por ello, no será posible pensar el ser sin la relación que supone el con y sin su referencia a la finitud que reclama la muerte de "sus" "miembros"13, fundamentalmente porque la comunidad, es decir, el ser, es con-stitución. Así, "la comunidad asume e inscribe...la imposibilidad de la comunidad" (2000 38), enunciado que reclama un pensamiento de la comunidad en su radical desobra y finitud, puesto que el ser es finito, sin medida, y la finitud misma es su medida desmesurada (2006 193-198). Se trata por ello de una exhortación a pensar de otro modo aquello que las experiencias políticas fundadas en nombre de lo común, negaron y clausuraron, haciendo de la comunidad una obra de muerte y enfrentándola por ello a su disolución.

Por esta razón, Nancy encontrará, en principio ${ }^{14}$, una conexión argumental con el concepto de soberanía en Georges Bataille, por cuanto - cómo él mismo lo formula - "la soberanía no es NADA" (2000 43), ya que ésta - que para Bataille es una experiencia - nos reenvía directamente a lo abierto de una exposición a un exceso de ser donde éste es abandonado: "la soberanía se expone y nos expone a un exceso que no es" (Ibid.), a una exterioridad irrecuperable, a un afuera inconmensurable. Esto sería, precisamente, aquello que suministra el ritmo de la "ontología de lo común" con la experiencia de una exterioridad radical, es decir, la nada. La comunidad, vendría así a posibilitar el tener lugar del espaciamiento de la experiencia del afuera ${ }^{15}$, asumiendo que dicho espaciamiento no es sin relación o, dicho de otro modo, antes que el lugar o el espacio propiamente tal, lo que

\footnotetext{
${ }^{13}$ Las comillas están puestas allí para marcar una distancia con la idea de propiedad y membresía como definición del ser-con de la comunidad, porque en realidad, una comunidad desobrada resiste precisamente estas ideas, en tanto reverberancias de inmanencia.

${ }^{14} \mathrm{Al}$ menos en La communauté désoeuvrée, ya que luego, particularmente en el balance que hace de su trabajo sobre la cuestión de lo común en $L a$ communauté désavouée (2016), tomará distancia explícita de esta particular lectura de Georges Bataille en quien ve una recusación sin reservas de la comunidad y lo político, ofreciendo, en cambio, una experiencia individual que no es capaz de comunicar con lo social. Por ello, a partir de sus trabajos publicados desde inicios de la década de los noventa, Nancy abandonará el motivo de la comunidad y comenzará a pensar la figura del seren-común.

${ }^{15}$ De carácter preindividual, no subjetiva, puesto que de lo que se trata es de diferencias singulares donde lo individual no es sino una "forma" de estas diferencias. En La communauté désavouée, esta idea volverá a aparecer para subrayar "la compartición de la cual las entidades discretas (individuos, personas) no son más que los aspectos, las puntuaciones" (2016 13).
} 
inaugura este espaciamiento es aquello que lo vuelve posible: la distancia y la relación entre singularidades, la comunicación de la comunidad, en tanto “(...) la comunidad es la conciencia extática de la noche de la inmanencia..." (2000 45). Así, en el planteamiento de Nancy, el lugar, o más precisamente, la circunscripción de la comunidad sería la de una "topología atópica" (Ibid.), es decir, un lugar-no-lugar que no es territorio sino la "arrealidad de un éx-tasis...así como la forma del éxtasis es aquella de una comunidad" (Ibid.). La conexión entre el éxtasis y la comunidad se configuraría en un movimiento en el que ambos se arrealizan de manera incesante, impidiendo, con ello, la inmanencia. Porque la comunidad no se realiza o, más bien, se desrealiza en una forma arreal que resiste la inmanencia fusional como condición del estar-en-común. Un «comunismo sin comunidad», en el sentido de un porvenir que siempre está viniendo en el seno de una colectividad: "es porque no deja de venir - aclara Nancy - que resiste sin fin a la propia colectividad y al individuo" (Id. 123). Esta misma formulación, será expuesta tres décadas más tarde como la necesidad de practicar "un arte de la fuga" (2016 161), un ir y venir entre obra y desobramiento.

Un pensamiento de la comunidad, en consecuencia, que no renuncia a pensar su límite, esto es, el punto en el que se comunican las existencias singulares, es precisamente el de una comunidad como el reparto, la compartición, irreductible a la comunión y a la comunidad de los hombres. Nancy (cf. 2000 45-54) agrega que lo que intenta indicar en este límite, es una experiencia, pero no una experiencia que hacemos, sino que nos hace ser, aspecto que luego reafirmará en La communauté désavouée ( $c f .2016$ 139-142) para indicar que lo común de la comunidad no es un "algo" que se pueda hallar, sino una experiencia, siempre ya compartida. Es la dimensión ontológica definida por el reparto, el espaciamiento que posibilita la comunicación de existencias singulares, al tiempo que revela el carácter inacabado del ser que precisamente nos expone como entes finitos. Desde este ángulo, lo común no sería más que esta exposición.

\section{Problemática prolongación o juntura de lo ético y lo político}

Pensar el problema de la comunidad como experiencia antes que como obra o realización, nos permite detectar la textura ética del problema ontológico del seren-común o ser-con, cuestión que Nancy no abordará de forma explícita sino hasta la publicación en 1996 de Être singulier pluriel ${ }^{16}$, donde se hace más clara la

\footnotetext{
${ }_{16}$ Muy posiblemente porque lo que buscaba en La communauté désoeuvrée, era una política a partir de su lectura de Georges Bataille y Maurice Blanchot, sin embargo, como el mismo "confiesa" en $\mathrm{La}$ communauté désoeuvrée, en su lugar lo que encuentra es una experiencia, radicalmente separada de la política, o que directamente la recusa.
} 
problematicidad compartida o la implicación recíproca entre ambos registros, al señalar que "no hay ética que sea independiente de una ontología...[puesto que] sólo la ontología puede ser ética en un sentido que no sea inconsistente" (2006 37), para más tarde agregar que "esta ontología debe ser, idénticamente, un ethos y una praxis" (2006 80).

El que no exista ética sin ontología, se esclarece si se piensa lo ético como ethos en sentido griego, esto es, como un modo de ser y conducirse en el mundo, de tal manera que, si la ética es precisamente esto - antes que un modo normativo del ser o un "atajo normativo" como lo ha planteado erróneamente Oliver Marchart (2009 210-214) - no puede formularse como tal sin la comparecencia a un modo del ser. Es lo que Nancy también piensa bajo la noción de mundo, proponiendo en definitiva otro modo de pensar, otro modo de ser o, más precisamente, una ontología radicalmente otra, en disposición polémica con la metafísica, puesto que lo que allí se juega es una concepción determinada del ser. Así, lo ético solo podría implicar un conducirse de tal modo en la medida que coliga una concepción de mundo, concepción que no es sino ontología, de sí y de su relación con él. Al revés, si la concepción de mundo no es al mismo tiempo o no coliga un ethos, no puede entonces haber consistencia, disociando el ser del pensamiento, el pensamiento del ser. Por ello es también praxis, por cuanto reenvía a una experiencia vivida, que implica a los sujetos, pero más directamente, a los cuerpos que se tocan al comparecer en sus existencias expuestas. Siguiendo esta ruta, es posible entender el enunciado según el cual, "no hay diferencia entre lo ético y lo ontológico: la «ética» expone lo que la «ontología» dispone” (2006 114).

Pensar de otro modo, implica, entonces, volver a interrogar aquello que ha sido proscrito o desalojado forzosamente del horizonte de problemas filosóficos y políticos, para inaugurar así un nuevo plano de problematicidad para la filosofíapolítica o para la filosofía como política, en la medida que la filosofía se da por problema la exposición de la existencia o el pensamiento del ser-con ${ }^{17}$ y la política es el modo en que comparecemos a esta exposición ( $c f$. Id. 37-44). Lo ético, en toda esta problematicidad, se entiende, así como sinónimo de una comparecencia que es responsabilidad, en tanto compartición del munus de la co-munidad, es decir, compromiso con una ontología, puesto que ser responsables es "estar comprometido[s] por su ser hasta el final de este ser, de tal forma que este compromiso, este conatus es la esencia misma del ser" (2006 198). El ser-en-común se define y constituye así, por una carga y no está a cargo de otra cosa que del cum que es nuestra morada, nuestra estancia.

Llegados a este punto, habría que retomar un aspecto de la problematización que tan sólo se ha esbozado al comienzo de este artículo, esto es,

\footnotetext{
${ }^{17}$ La filosofía como el pensamiento del ser-con y el pensar-con como filosofía.
} 
el problema de lo político. Y este "sólo esbozo" no es una casualidad, por cuanto intenta mostrar precisamente la dificultad que su problematicidad comporta al interior del pensamiento de Jean-Luc Nancy. Habría, entonces, que intentar examinar con precaución este problema, teniendo en cuenta en primer lugar que lo común no puede ser reducido a una «nueva» especulación metafísica, o a una filosofía sin politicidad como siendo sin materialidad, sobre todo si se considera que cada vez que Nancy intentó -hasta ahora- recomenzar la problematicidad de lo común, lo ha hecho provisto de un diagnóstico del presente que constata la profunda catástrofe que nos recorre. En La communauté affronteé, por ejemplo, Nancy dirá, sin lugar a dudas, que "el estado actual del mundo no es una guerra de civilizaciones. Es una guerra civil: es la guerra intestina de una ciudad, de una civilidad..." (2007 9), la de un mundo que se desgarra al no poder "hacer lo que debe: a saber, un mundo...vale decir, un espacio de sentido" (Id. 12). A propósito de esta "desgarradura del mundo", Nancy avizora, en el mismo trabajo, dos problemas que revelan la riqueza de sentido comprendida en el vocablo francés afffronteé. El primero -de características ontológicas-, es presentado como un "programa del trabajo de pensamiento" (Id. 13), que intenta precisamente pensar el enfrentamiento como "una ley del estar-en-común y su sentido mismo" (Ibid.). Mientras que el segundo -de características propiamente éticas y políticas- prevé la destrucción como posibilidad de este enfrentamiento, comprometiendo esta misma posibilidad, así como "la del estar-en-común o del coestar" (cf. Id. 10-15). De un lado, el problema de cómo pensar la desgarradura del mundo, del otro, la problematicidad implicada en el afrontamiento de esta desgarradura que es lo común, sin que implique por ello la completa devastación de lo desgarrado como su posibilidad más próxima. El primer problema, implica pensar la desgarradura del "con" como un espacio originario/arcaico, recorrido por una disyunción, en tanto afuera que es nada, y donde "no puede haber sino fuerzas que se enfrentan en virtud de su juego mutuo y de presencias que se separan en virtud de que siempre han de volverse otra cosa que meras presencias" $(I d .13,14)$. Se trata por ello de un trabajo del pensamiento capaz, no tan sólo de examinar la disyunción/desgarradura del ser en su textura ontológica, sino de ir más lejos, desplazándose hasta el umbral donde ética y política se vuelven indistinguibles, es decir, hacia la politicidad del problema de la comparecencia al carácter diferencial de la existencia.

Por ello Nancy se preguntará "cómo volvernos capaces de mirar a la cara nuestro vacío y nuestro enfrentamiento" (2007 14), no para extraviarnos en una recepción nihilista del vacío o tomar partido en un enfrentamiento del que ya somos parte de manera constitutiva, "sino para hallar, pese a todo, la fuerza de enfrentarnos, primero con conocimiento de causa" (Ibid.), es decir, accediendo al sentido del enfrentamiento, esto es, al carácter ex-tático del ser que es el ser-en- 
común, de manera tal que luego "podamos realmente encontrarnos" (Ibid.). No es posible entender este llamado de Jean-Luc Nancy sin escuchar las intensidades que lo pueblan, los lugares desde los que nos exhorta a pensar la singularidad plural que nos constituye (no sin precaución, sino exhibiendo su riesgo), delineando así un problema ontológico, al mismo tiempo que sus derivas éticas y políticas, aun cuando se trate de "cosas análogas" (cf. Id. 14), donde se entrecruza una necesidad, en su doble sentido: "nuestra menesterosidad y nuestra obligación” (2007 15).

Lo político dentro de esta "otra ontología", de algún modo se encuentra inclinado sobre su despliegue, precisamente con objeto de volverlo a pensar estableciendo su retrait o re-trazado (1981), al constatar que "delante o detrás de lo político, hay esto: a saber, lo «común», lo «conjunto» y lo «numeroso»" (Id. 22). De todos modos, la ambigüedad del vocablo francés es llamativa, por cuanto pensar el retrait como retirada es igualmente legítimo, y como vemos, el re-trazado coincide con la retirada de lo político en relación a la "evidencia" ontológica de la comparecencia. En La communauté désavouée, esto será del todo explícito, al afirmar que lo común significa "que no hay ser singular sin otro ser singular, y que entonces hay, dicho en un léxico inapropiado, una «socialidad» originaria u ontológica (el zoon politikon es segundo con respecto a esta comunidad)..." (2000 $56,57)$, para luego afirmar que la comunidad es la resistencia a todo intento de sustancialización y totalización. Así, lo político queda "delante o atrás" (2007 21) de esta "evidencia", pero sin coincidir con ella, disponiéndonos a pensarlo de otro modo que bajo su representación tradicional ligada al Estado y sus instituciones, o - como aclara en $L a$ communauté désavouée - , a la democracia representativa (cf. 2016 82). Y este "otro modo", no es sino tributario de aquello que en 1981 Jean-Luc Nancy junto a Philippe Lacoue-Labarthe, llaman "la interrogación acerca de la esencia de lo político" (1981 54). De todos modos, como aclararán en el Avertissement a Le retrait du politique, publicado dos años más tarde, la pregunta por la esencia de lo político supondrá la necesidad de interrogar "lo que hace posible la relación social como tal" (1983 139). Así, la cuestión de lo político consistirá en argumentar que aquello que lo recorre es una relación de desligadura, antes que una relación simplemente dada. Desde este ángulo, la relación convocaría el problema esencial de la dis-yunción: "en términos más precisos, la cuestión general del retiro involucra al pensamiento de la «dis-sociación»...un pensamiento de la «relación» (o del «lazo social») como constituido por una separación o una «desligazón»" (Id. 139, 140). Toda esta tentativa se despliega para evitar plantear un nuevo fundamento de lo político, al mismo tiempo que intentar impedir que lo político se presente como la consecución de un lazo más originario. Interrogar la relación, entonces, será un modo de interrogar el paso a la comunidad y al sujeto; pensar la dis-sociación que recorre lo político. 
Siguiendo esta problematización, y advertidos de la textura ontológica implicada en el pensamiento de lo común, es posible volvernos sensibles a una cierta sospecha o desconfianza de Nancy por la política "a secas", sobre todo porque toma distancia de la posibilidad involucrada en que "la comunidad pueda ser, como tal y directamente «política» (2016 26). Esta desconfianza es posible rastrearla muy tempranamente en su pensamiento - como hemos visto, incluso antes de La communauté désoeuvrée, en los trabajos de colaboración con LacoueLabarthe-, donde se piensa el riesgo de lo político antes que su promesa, puesto que lo que se tiene a la vista es el fascismo, el comunismo estalinista, y en general, la guerra como expresión más extrema de la desgarradura de la comunidad, pero por sobre todo, lo que se formula como "un cierto cumplimiento de lo político" (1981 55), que exige levantar acta de su clausura, reconociendo en el "socialismo real", "la figura extenuante, extenuada, de la imposición filosófica" (1981 55).

Teniendo esto en cuenta, no resulta extraño -como el mismo Nancy reconoce al mirar en perspectiva La communauté désoeuvrée- que lo político aparezca allí de una manera muy escueta, para marcar un cierto orden de consecuencias de lo que el libro establecía ( $c f .2016$ 38). Pese a esto, Nancy prefiere seguir sosteniendo la diferencia entre ontología y política y en sus últimos trabajos sobre el problema de lo común, dirá que "la polis ya no es para nosotros el lugar de la entera puesta en juego del sentido, como lo ha podido ser en tanto religión civil de los hombres libres de la muy diferenciada organización ateniense" (2016 164).

\section{Umbral}

Si se quisiera permanecer en la problematicidad abierta por Jean-Luc Nancy, habría que reconocer el primado ontológico de su pensamiento, al poner en el centro la cuestión de lo común, en tanto ser-con o mitdasein. Al mismo tiempo, habría que asumir una distancia radical con toda forma de figuración de lo político, esto es, una disposición polémica con toda pretensión de hacer de lo político una esfera técnica, programable, controlable o gubernamentalizable, al igual que se procede con la gestión de las poblaciones, la economía y el mercado. Antes bien, nos encontramos frente a una politicidad de la existencia que intenta comparecer al carácter singular-plural del ser, es decir, que al mismo tiempo comporta una eticidad, una experiencia o un modo de ser-en-el-mundo, que vuelve ética y política cuestiones análogas y por ello, indisociables. En otras palabras, un "comunismo" que, sin embargo, no reenvía hacia un proyecto político sino a una proposición ontológica que lo piensa como lo propio y arcaico del ser, al mismo 
tiempo que como aquello por-venir, que llega, como acontecimiento ${ }^{18}$, convocando a algo que no está dado, aun cuando “algo de esta conjunción” (2010 147) ya lo está: el con, el estar-juntos, como aquel espacio de la diferencia y la relación, donde no es posible asegurar destino alguno.

En La comparution, Nancy dirá, en relación a este punto, que no hay nada más desnudo que lo político, "nada más expuesto: a la dispersión... a la finitud de toda destinación y a la indigencia de la existencia. Nada más desnudo. Nada más común" (2014 103). Por ello, lo político, desde aquí, no promete ni puede prometer la reunión, la dirección de las extremidades donde la existencia tiene lugar, y más bien la política sería aquel lugar donde se jugarían "relaciones por venir...[que] deberán responder a espacios de libertades desconocidos" (2016 162) y el comunismo, "el nombre del deseo de crear una verdad simbólica de la comunidad en la que la sociedad se reconozca en falta en todos los aspectos" (2009 73). En este sentido, se trata de una política «otra»-o, más precisamente, de una politicidad-, en la medida que asume el co del comunismo como "una cuestión ontológica" (2010 148) y, por tanto, un «comunismo sin comunidad» como lo apropiado, es decir, como lo más propio del ser:

[...] comunismo significa la condición común de todas las singularidades de los sujetos, es decir, de todas las excepciones, de todos los puntos singulares cuya red hace un mundo (una posibilidad de sentido). No corresponde a lo político ${ }^{19}$. Está antes que cualquier política...El comunismo es un principio de activación y limitación de la política (Id. 150).

Esta manera de pensar la cuestión, exigiría, sin embargo, algunas condiciones. En primer lugar, tener en cuenta que, para Nancy, el problema decisivo se encuentra en la necesidad de una crítica sin reservas de la tradición filosófico-política, es decir, de la metafísica. Tener esto en cuenta resulta crucial, por cuanto el trabajo deconstructivo de la metafísica en relación a un nuevo concepto de lo político, es un problema que aun permanece abierto y por ello, aun está por hacerse.

En segundo lugar, un nuevo concepto de lo político, no identificado con la polis, sino con la condición relacional de la existencia, de manera tal que logre explicar su devenir agonal, en el doble trazado conformado por la asociación/disociación que no es otra que la "estructura" de la diferencia ontológicamente inscrita. En palabras sencillas, no se trata de afirmar la esencia de

\footnotetext{
${ }^{18}$ En esta lectura, acontecimiento no sería sino una "expresión fenoménica" o variante conceptual de lo político, como "política de lo político".

${ }^{19}$ Nancy está usando aquí la denominación de "lo político" como una manera de hablar y no está pensándolo en los términos ontológicos en los que acabamos de desarrollar la argumentación de este artículo.
} 
lo político en su figuración agonal, sino de concebir este carácter como posibilidad de la relación misma. Lo que habría que pensar, en este sentido, es el carácter de la relación, del "entre" del "con" como fuerza disyunta (el co en cuanto dis, es decir, disposición antes que composición). Al respecto, Nancy (cf. 2016 167) nos recuerda que el comes y el contra son posibilidades del cum, es decir, lo agónico y lo comunal como posibilidades existenciales del ser, de su carácter expuesto. No hay, ni podría haber, por tanto, figura destinal de lo político. Antes bien, el riesgo del cum. Esta misma distinción, es posible observarla casi al final de La comparution cuando Nancy se refiere a la injusticia absoluta como figura filosófica para la explotación, la opresión o el exterminio, describiéndola como la "dura esquirla de una «desnaturalización» de lo político inscrita en el corazón de lo político y como una de sus propias posibilidades" (2014 105), de manera tal que, allí, justamente donde se niega la partición del cum, su radical consistencia como pura diferencia, allí se niega la existencia comprometiendo el en de lo en-común. $\mathrm{Y}$ es frente a esta negación que comparecemos, también, ante nosotros mismos. Este es el riesgo de lo común, su condición diferencial y por ello, incalculable e indomesticable.

Teniendo esto en cuenta, la afirmación de lo político en Jean-Luc Nancy no podría consistir sino como una politicidad comprometida con una retirada: sólo otra política (otro concepto de lo político) podría enfrentar lo político en su riesgo, de manera tal que a partir de ella se dibuje y se decida una figura. Así, la urgencia no sería "otra abstracción política" (2006 41), sino más bien reconsiderar el sentido mismo de "política", aun cuando, para conseguirlo se requiera indefectiblemente una nueva "imaginación política". Una forma bastante clara en que Nancy delinea esta posición es a través de una pregunta que califica como "la doble pregunta crucial de lo en-común" (2014 106), esto es, “¿cómo excluir sin figurar? ¿Y cómo figurar sin excluir?" (Ibid.); pregunta formulada luego de exponer cómo es que la comunidad excluye su propio fundamento infundado, pretendiendo así forcluir su fondo que es la hiancia del ser, aquella en que se funda toda "sociación". Si se piensa este problema en relación a una "otra política" o según su re-trazado, habría que reconocer el vértigo de la ausencia de un territorio seguro para su actividad, su naturaleza abisal, expuesta, teniendo a la nada por fundamento, de manera tal que ya no sería posible presuponer ninguna consistencia del ser-en-común. Y al mismo tiempo, sostener la diferencia como aquel trazado de la exterioridad del con, sin intentar su cierre (aun cuando este intento esté siempre ya condenado a la catástrofe y el fracaso. La historia del siglo XX es nuestro mejor ejemplo), obteniendo como resultado que la desfundamentación de lo político es, al mismo tiempo, una desfundamentación de lo social, donde lo político permanece como su causa ausente, es decir, una causa que sólo es posible verificarla a través de sus efectuaciones. En este preciso sentido, es posible reconocer en Jean-Luc Nancy una 
invitación a pensar una política con fines, pero sin fin, puesto que no es posible domesticar, programar o superar lo político; aquello es lo que marca la hiancia de la existencia, la condición siempre fallida de toda positividad, la profunda fractura que recorre todos los intentos de sutura por la política.

En consecuencia, si no es posible establecer una dirección para una política determinada, su sentido tendría que encontrarse en una politicidad de la existencia que comparezca al carácter diferencial del ser, a su condición desfundamentada. No podríamos, sin embargo, hacer de este planteamiento una lectura normativa, por cuanto su eticidad debiera más bien entenderse en tanto ethos, cuyo único sentido es la comparecencia al carácter diferencial y desfundamentado del ser-con; eticidad que es un modo de ser, en tanto modulación de la diferencia que no cesa de diferenciarse en el tocarse de las singularidades: ¿cómo, entonces, a partir del reconocimiento de esta, nuestra condición expuesta, comparecemos frente a aquello que precisamente somos o nos ha hecho ser?. Nuevamente, el riesgo del cum, puesto que, acaso una ética que intenta hacerse cargo de este, nuestro ser singular-plural, no pueda evitar pasar, también, por la interrogación, a su vez, de las consecuencias políticas de un ethos de la comparecencia al ser, toda vez que esta comparecencia es un encuentro con aquello que clausura y niega su posibilidad. No se trataría, en este caso, de una determinación de la política, aunque sí implicaría que nos hiciéramos cargo de las consecuencias de una eticidad como esta, donde su politicidad no podría sino ser agonal $^{20}$. Muy alejado y completamente enfrentado, entonces, a una concepción que intente revestir de una pasta moral a la política o de politizar la moral, reconduciendo el problema ontológico a los derroteros habituales del sujeto histórico, el humanismo, y por que no decirlo con toda claridad, del liberalismo y su imantación al dispositivo totalitario de la soberanía que lo fundamenta.

Finalmente, pensar con Jean-Luc Nancy la problematicidad involucrada en la juntura onto-ético-política, podría permitirnos dar tratamiento o hacernos cargo del acuciante problema del por-venir de nuestro mundo: de un lado, nos deja arrojados a la "espaciosidad de la libertad", como política de lo político. Del otro, nos notifica acerca de la profunda catástrofe contemporánea que convierte el pensamiento de lo común en una necesidad apremiante, al mismo tiempo que hace de él una exigencia por interrogar a este, nuestro mundo y las posibilidades mismas de la filosofía.

\footnotetext{
${ }^{20}$ Recordemos que para Nancy en La communauté désavouée ( $c f .2000$ 102), la comunidad es la resistencia misma.
} 


\section{Bibliografía}

Blanchot, Maurice. “Le communisme sans héritage”. Revue Comité, 1 (1968): 13-16.

Heidegger, Martin. Ser y tiempo. Traducción de José Gaos. México: Fondo de Cultura Económica, 2007.

Lacoue-Labarthe, Philippe y Nancy, Jean-Luc. El pánico político. Traducción de Cristóbal Durán y Nicolás Gómez. Buenos Aires: Palinodia - La Cebra, 2013.

Lacoue-Labarthe, Philippe y Nancy, Jean-Luc. "Retrazar lo político". Nombres, Revista de Filosofía, XXI/26 (2012): 51-67.

Lacoue-Labarthe, Philippe y Nancy, Jean-Luc. "La "retirada" de lo político". Nombres, Revista de Filosofía, X/15 (2000): 36-46.

Lacoue-Labarthe, Philippe y Nancy, Jean-Luc. "Avertissement". Le retrait du politique. París: Galilée, 1983. 9-10.

Marchart, Oliver. El pensamiento político posfundacional. La diferencia política en Nancy, Lefort, Badiou y Laclau. Traducción de Marta Delfina Álvarez. Buenos Aires: Fondo de Cultura Económica, 2009.

Nancy, Jean-Luc. La comunidad revocada. Traducción de Luis Felipe Alarcón. Buenos Aires: Mardulce, 2016.

Nancy, Jean-Luc y Bailly, Jean Christophe. La comparecencia. Traducción de Cristina Rodríguez Marciel y Jordi Massó Castilla. Madrid: Averigani, 2014.

Nancy, Jean-Luc. "Comunismo, la palabra". Hounie, Analía. (comp.). Sobre la idea del comunismo. Traducción de Alcira Bixio. Buenos Aires: Paidós. 2010. 145153.

Nancy, Jean-Luc. "Democracia finita e infinita". Agamben, Giorgio y otros. Democracia, ¿en qué estado?. Traducción de Matthew Gajdowski. Buenos Aires: Prometeo. 2009. 67-79.

Nancy, Jean-Luc. La comunidad enfrentada. Traducción de Juan Manuel Garrido. Buenos Aires: La Cebra, 2007.

Nancy, Jean-Luc. Ser singular plural. Traducción de Antonio Tudela. Madrid: Arena, 2006.

Nancy, Jean-Luc. La creación del mundo o la mundialización. Traducción de Pablo Perera Valemazán. Barcelona: Paidós, 2003.

Nancy, Jean-Luc. La comunidad inoperante. Traducción de Juan Manuel Garrido. Santiago: Lom, 2000.

Nancy, Jean-Luc. "Conloquium”. Esposito, Roberto. Communitas. Origen y destino de la comunidad. Traducción de Carlo Rodolfo Molinari. Buenos Aires: Amorrortu, 1998. 9-19. 